\title{
De Geometria e Geometrizando: Caminhos para a Criatividade
}

\author{
Of Geometry and Geometrizing: \\ Pathways to Creativity
}

\author{
Neusa Cavalcante \\ Doutora em Arquitetura e \\ Urbanismo \\ Professora Adjunta I, \\ Departamento de Projeto, \\ Expressão e Representação, \\ Faculdade de Arquitetura e \\ Urbanismo da Universidade de \\ Brasília \\ neusa.cavalcante2@gmail.com
}

Maria Cláudia Candeia
PhD em Arquitetura e
Urbanismo
Professora Adjunta I,
Departamento de Projeto,
Expressão e Representação,
Faculdade de Arquitetura e
Urbanismo da Universidade de
Brasília
mariaclaudiacandeia@gmail.com

Eliel Américo Santana da Silva Doutor em Urbanismo

Professor Adjunto I,

Departamento de Projeto,

Expressão e Representação,

Faculdade de Arquitetura e

Urbanismo da Universidade de

Brasília

americoeliel@gmail.com

\begin{abstract}
RESUMO
0 artigo apresenta um apanhado de experiências de ensino e descreve os princípios e métodos adotados na disciplina de Geometria Construtiva da Faculdade de Arquitetura e Urbanismo da Universidade de Brasília (UnB). Por meio do estudo de modelos e padrões geométricos, a disciplina foi criada com o objetivo de exercitar o raciocínio espacial e desenvolver a capacidade de abstração, propondo situações aplicáveis à arte e à arquitetura. Considerando as dificuldades no ensino de composição plástica nos cursos de arquitetura do país, o artigo tem como objetivo apresentar um método que, servindo de aporte às disciplinas de projeto e representação, possa contribuir para o debate em torno de melhorias curriculares. São apresentados as etapas de elaboração dos trabalhos, os resultados, as vivências e as respostas às estratégias pedagógicas adotadas. 0 método desenvolve-se mediante uma série de exercícios conceituais e práticos apoiados em aulas expositivas que servem de motivação e suporte para cada um dos temas.
\end{abstract}

Palavras-chave: geometria; geometria construtiva; educação artística; criatividade.

\section{ABSTRACT}

The essay gives an overview of teaching experiences and describes principles and methods adopted in the Constructive Geometry, course of the Faculty of Architecture and Urbanism of the Universidade de Brasília (UnB). Through the study of models and geometric patterns, the course was created with the goal of practicing spatial reasoning and developing capacity of abstraction, proposing scenarios applicable to art and architecture. Considering the difficulties in plastic composition education in architecture courses of the country, this essay aims to present a method that can support representation and studio design courses contributing to curriculum improvement debate. It is presented the essential steps of elaboration process, results, experiences and the responses to the teaching strategies. The method unfolds in a series of conceptual and practical exercises in combination with expository lessons that serve as motivation and support for each theme.

Keywords: geometry; constructive geometry; art education; creativity. 


\section{OS PREÂMBULOS}

0 atual momento histórico, definido por Zygmunt Bauman (2001) como "modernidade líquida", em que o tempo se sobrepõe ao espaço, fazendo com que nos movimentemos sem sair do lugar e vivamos rodeados de sinais confusos propensos a mudar com rapidez e de forma imprevisível, coloca para nós, professores, a necessidade de uma profunda reflexão sobre nossas práticaspedagógicas. Trata-se de desenvolver metodologias de ensino capazes de dar respostas para as novas demandas da sociedade que se desenvolve em um cenário de imprevisibilidade.

Parece-nos que a palavra-chave capaz de promover melhor inserção profissional no novo arranjo social e econômico é criatividade. Mas como criar metodologias de ensino voltadas para os novos desafios impostos pela globalização? Mais ainda, como fazer virem à tona as emoções dos jovens alunos, como motivá-los para a aquisição de conhecimentos e, principalmente, como estimulá-los a serem mais criativos?

Ao invés de concentrar esforços na disseminação de informações, muitas vezes isoladas e desconexas, outras vezes contaminadas por uma lógica do passado que não faz sentido para os jovens alunos e não deixa claro seu verdadeiro significado teórico e sua importância para a futura prática profissional, melhor seria tentar desenvolver estratégias capazes de estimular a criatividade. Em lugar de treinados para ser personagens de cenários já desenhados, os estudantes devem ser estimulados a antecipá-los, recriá-los. Mais do que aprender a seguir dogmas, eles devem se sentir libertos para sonhar e criar.

0 principal objetivo da educação artística talvez não resida diretamente nos princípios da produção da arte, mas na emancipação e abertura da personalidade do aluno, de seu autoconhecimento e de sua autoimagem em relação às tradições incrivelmente ricas da arte e do mundo em que vivemos. (PALLASMAA, 2013, p. 22).

Após um longo período à frente da disciplina Geometria Construtiva, da Faculdade de Arquitetura e Urbanismo da Universidade de Brasília (FAUUnB), pretendemos, com este artigo, explicitar nossas experiências de ensino, e, sobretudo, descrever os princípios e métodos que têm sido adotados ao longo dessa trajetória.

Pode-se definir a Geometria Construtiva, ou simplesmente GC, como é chamada pelos alunos, como um processo pedagógico experimental, fruto do resgate de experiências realizadas, na década de 1960, por Athos Bulcão e, na década de 1990, por Jayme Golubov na Universidade de Brasília (UnB). Obrigatória para os alunos recém-ingressos no curso de Arquitetura e Urbanismo e aberta a todos os estudantes da UnB, a disciplina, que se desenvolve por meio de exercícios apoiados em aulas conceituais e de repertório sobre a arte abstrata, tem como objetivos desenvolver a acuidade tátil-visual; exercitar o raciocínio espacial; desenvolver a capacidade de abstração; promover a manipulação e a construção das formas geométricas. 
Muito embora possa parecer pretensioso, tencionamos ainda que o próprio fazer experimental possa tocar a dimensão emocional dos jovens, estimulando o amor pelas artes e a arquitetura e, sobretudo, abrindo possibilidades para que se tornem espíritos criativos.

\section{OS PRINCÍPIOS}

\subsection{O olho no olho}

Apesar de o número de vagas no ensino superior brasileiro público e privado ter aumentado significativamente nos últimos anos ${ }^{1}$, trazendo como consequência uma relação professor-aluno bastante discrepante, é importante, sobretudo nas disciplinas práticas, que sejam valorizadas as oportunidades de garantir a identidade dos alunos. Nos cursos de artes, é fundamental manter uma relação de proximidade entre os professores e os alunos, e seus respectivos contextos sociais. Apesar de demandar maior esforço docente, a orientação individual, a relação olho no olho, deve ser preservada nos ateliês de artes e arquitetura. Nesse sentido, nas turmas de Geometria Construtiva, por vezes com mais de 50 alunos e apenas uma aula semanal de 4 horas, as poucas e concisas aulas teóricas coletivas são distribuídas ao longo do semestre, garantindo-se, nas aulas práticas de ateliê, um atendimento individualizado.

Figura 1: registro de atendimento em sala de aula.
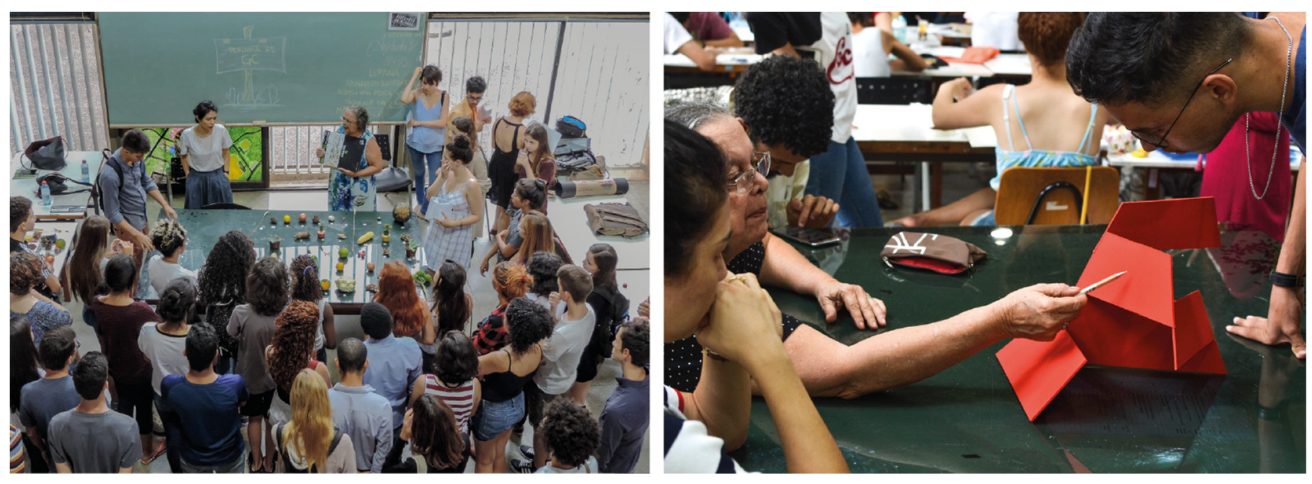

Fonte: fotografia de Gabriel Lyon (2018).

Constantemente impactada por grande quantidade de informações e imagens, a nova geração tende, em geral, a apresentar baixa capacidade de concentração. Assim, as aulas expositivas acontecem sempre após o início do trabalho criativo, pois, como se vem observando, o aproveitamento é tanto maior quanto mais os alunos estiverem conscientes dos problemas e envolvidos na busca de suas soluções.

\footnotetext{
${ }^{1}$ Segundo o Instituto Nacional de Estudos e Pesquisas Educacionais Anísio Teixeira (Inep), o número total de matrículas no ensino superior brasileiro cresceu de $81 \%$ entre 2003 e 2012. Disponível em: http://g1.globo.com/educacao/noticia/2013/10/numero-de-matriculas-no-ensino-superior-cresce-81-em-dezanos.html. Acesso em: 01. fev. 2019.
} 
Os trabalhos em equipes, sempre pequenas, são poucos, e realizados após o desenvolvimento dos trabalhos que chamamos de fundadores por serem estes os que inauguram a metodologia de ensino, da qual falaremos adiante.

\subsection{As mãos inteligentes ${ }^{2}$}

Por se tratar de uma disciplina de expressão e representação, voltada para um curso que tem as artes visuais como pressuposto, surge a necessidade de potencializar os mecanismos de apropriação do mundo físico, ou seja, de promover uma melhor observação das formas que nos rodeiam.

Apesar do importante papel da tecnologia da computação, entendese que o processo de produção artística é consolidado por meio de uma experimentação que, extrapolando o aspecto visual, deve envolver os demais sentidos. Como, no caso das artes visuais, o tato merece ser mais estimulado, é imprescindível que os exercícios sejam realizados com o uso das mãos. Assim, além de funcionarem como meio de aprimoramento da percepção visual, eles propiciam o desenvolvimento da coordenação motora fina, geralmente relegadados programas brasileiros de ensino fundamental e médio.

Figura 2: registro dos exercícios práticos feitos em atelier.
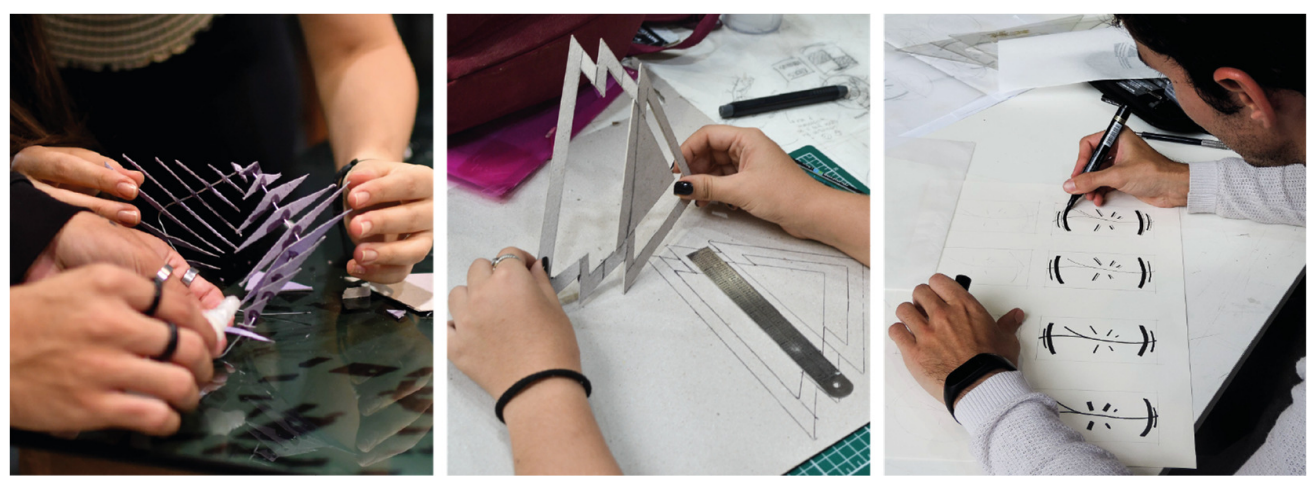

Fonte: fotografia de Gabriel Lyon (2018).

A relação das mãos com a capacidade humana de pensar foi assim descrita por Gaston Bachelard: "[...] as mãos têm seus sonhos e pressupostos. Elas nos ajudam a entender a mais profunda essência da matéria. É por isso que elas também nos ajudam a imaginar formas da matéria" (apud PALLASMAA, 2013, p. 18). 0 papel das mãos como instrumentos de produção de conhecimento foi ressaltado ainda, de forma poética, por José Saramago, no livro A caverna:

São poucos os que sabem da existência de um pequeno cérebro em cada um dos dedos da mão, algures entre a falange, a falanginha e a falangeta. Na verdade, aquele outro órgão a que chamamos cérebro [...] nunca conseguiu produzir senão intenções gerais, vagas, difusas, e sobretudo pouco variadas, acerca do que

2 Título parafraseado do livro As mãos inteligentes: a sabedoria existencial e corporalizada na arquitetura, de Juhani Pallasmaa. 
as mãos e os dedos deverão fazer [...] Para que o cérebro da cabeça soubesse o que era a pedra, foi necessário primeiro que os dedos a tocassem, lhe sentissem a aspereza, o peso e a densidade, foi preciso que se ferissem nela. (2000, p. 82, 83).

Assim, todos os trabalhos desenvolvidos no ateliê de Geometria Construtiva, desde a concepção até a arte final, são feitos com as mãos, portanto sem o auxílio dos fantásticos softwares que, ao tornarem o trabalho mais fácil, deixam de servir como estimuladores de certas habilidades humanas inatas.

\subsection{As exposições}

A ideia para a realização da primeira mostra Geometrizando, que ora chega à sua nona edição, surge da constatação de que a Geometria Construtiva produz, como resultado de seu conteúdo e sua metodologia didático-pedagógica, um expressivo material que merece ser divulgado para além das fronteiras da FAU-UnB.

Figura 3: exposição dos trabalhos dos alunos de Geometria Construtiva na galeria Christina Jucá, FAU-UnB.

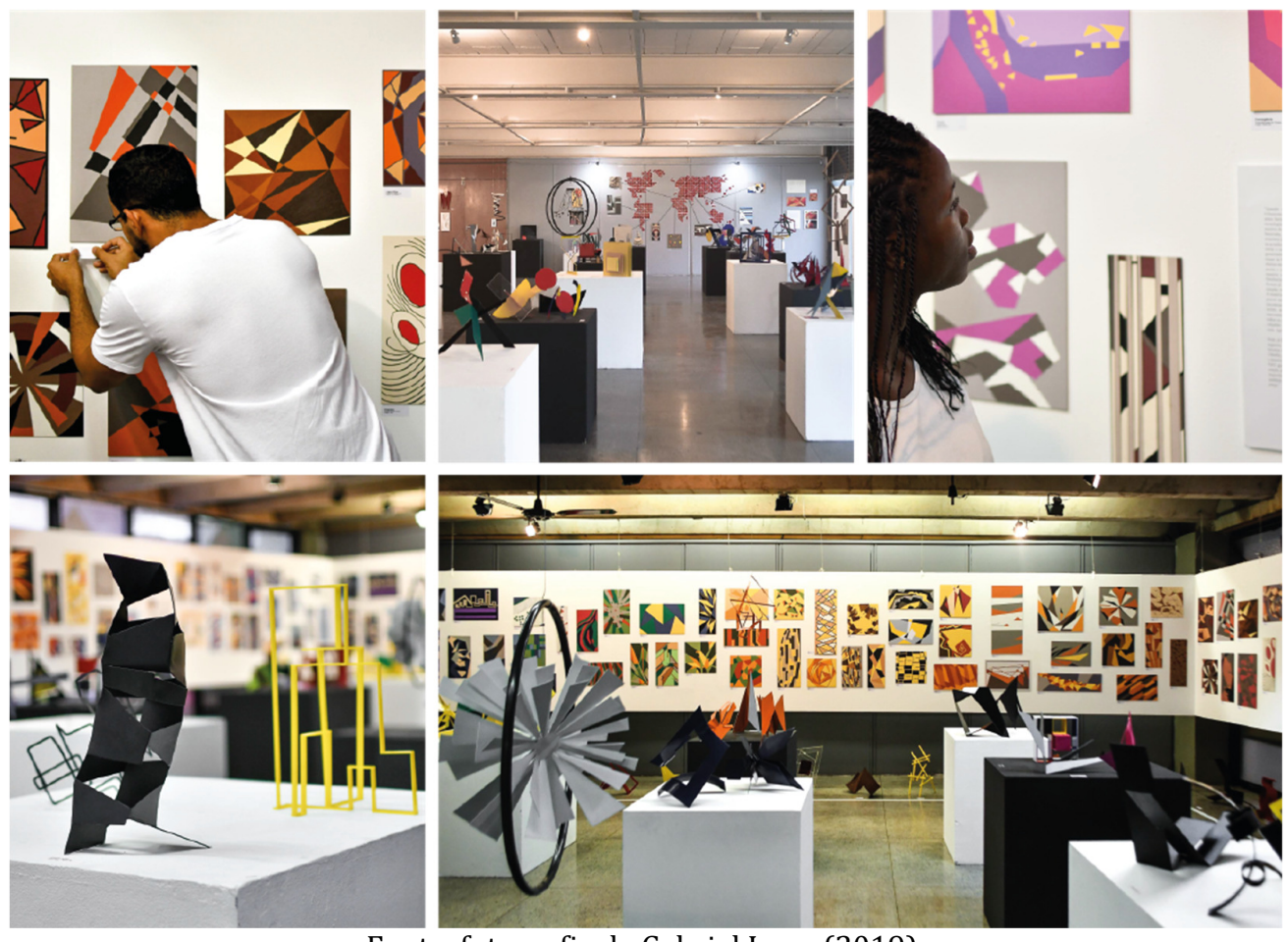

Fonte: fotografia de Gabriel Lyon (2019).

Ao ser tornada pública, a obra de arte, como suporte de significados, impõe-se como um tipo de linguagem por meio da qual se estabelece um intercâmbio com os outros homens. Além de "objeto-em-si", que define a existência física da obra, com os seus respectivos atributos objetivos, e de "objeto-para-si', em que se destacam as prerrogativas intelectuais e sensíveis que a obra desperta no sujeito, a obra de arte, segundo o arquiteto e 
professor Matheus Gorovitz (1998), realiza-se como "objeto-em-si-e-para-si" no momento em que se dá a consciência do papel social do sujeito e, portanto, da necessidade que o artista tem de se comunicar.

Além de servir para melhorar a autoestima e a autoconfiança, conforme reconhecido pelos próprios alunos, essas iniciativas representam um meio, ainda que tímido, de prestar contas da produção acadêmica à sociedade, indo ao encontro do espírito de transparência que deve prevalecer nas instituições públicas.

\subsection{Os batismos}

Um princípio, adotado mais recentemente, diz respeito à solicitação de que os alunos nomeiem seus trabalhos. Esse ato aparentemente simples de batizar - palavra cujo significado em grego é imergir - possibilita um efetivo mergulho, uma apreciação acurada ou, melhor dizendo, um encontro mais íntimo do aluno com sua obra.

Figura 4: trabalhos produzidos pelos alunos de Geometria Construtiva. Título dos trabalhos, da esquerda para a direita, de cima para baixo: Blues, Supernova, Shodô, Carnaval, Velejando e Espaço-tempo.
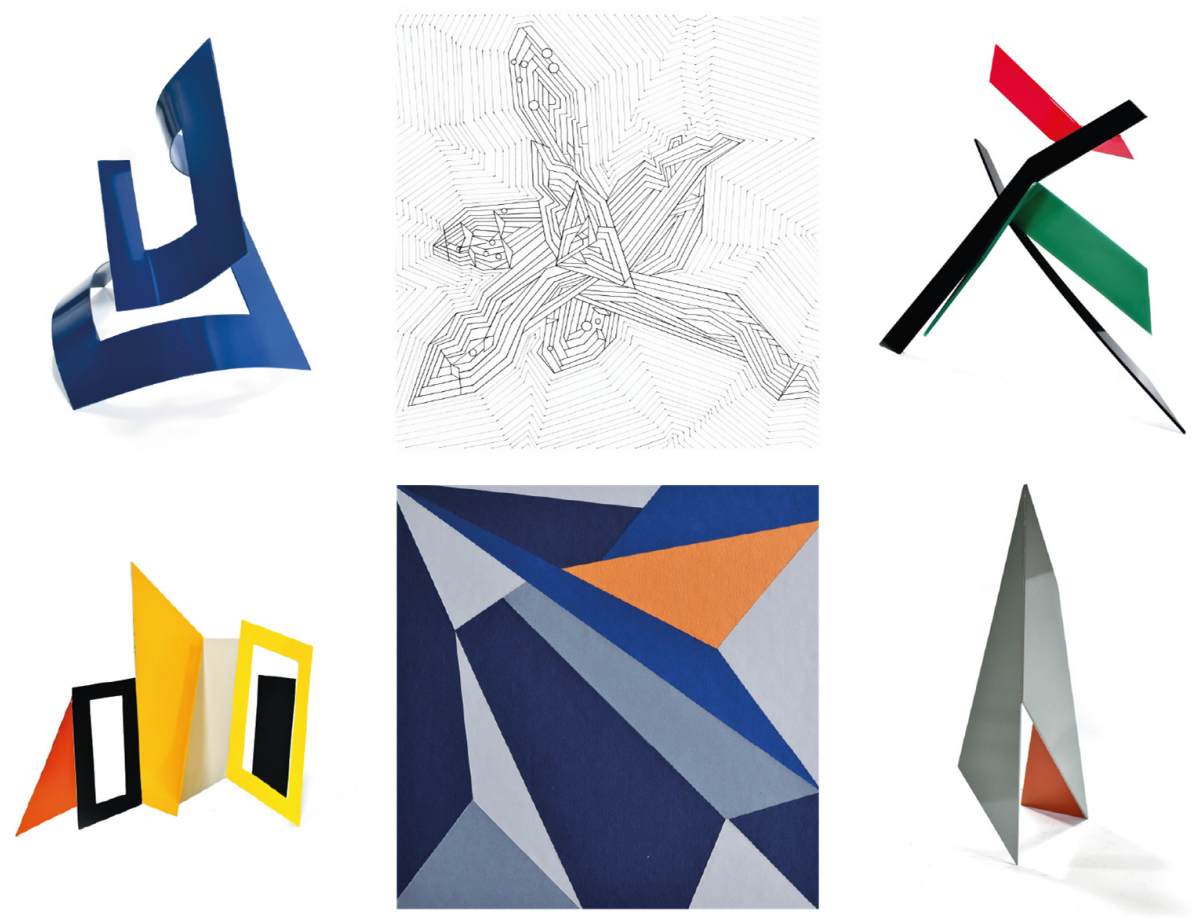

Fonte: fotografia de Gabriel Lyon (2019).

Durante a pausa para a escolha desses títulos, em que se estabelece uma relação muito estreita entre o aluno e a obra, acontece o que Gorovitz (1998) chamou de "objeto-para-si". Despertados intelectual e sensorialmente pelas formas e cores de suas composições, os alunos acabam realizando, por meio de diferentes analogias formais e cognitivas, uma nova leitura dos 
objetos produzidos anteriormente, o que contribui para conscientizá-los sobre o valor de suas obras. Com base em depoimentos dados por alunos em sala de aula, percebe-se que essa imersão faz aflorar muito do que há de escondido no emocional de cada um deles, atestando o êxito dessa estratégia.

\begin{abstract}
Eu comecei o semestre, desculpem admitir isso, sofrendo muito por causa de GC, quantas inúmeras vezes eu chorei de raiva tentando entender o que eu ia aprender com isso, porque, sério, eu tive uma dificuldade tremenda nos projetos; nossa, me tirou o sono, eu não sabia muito bem desenho realista, nem mesmo usar lápis de cor, não imaginava como chegar ao nível de geometrização dos trabalhos [...] mas, passando por tudo isso e apresentando o meu 2D, eu digo com muita felicidade e um alívio tremendo que estou orgulhosa de mim e do resultado. Esse trabalho representa a minha estrela, a Geometria Construtiva permitiu que eu chegasse nesse estágio de evolução, com essa explosão de brilho que eu enxergo em mim agora, me permitiu chegar ao meu instante SUPERNOVA. (Depoimento da aluna Eduarda Kelly Cavalcanti Nascimento Borges. Título da obra: Supernova, 2ำ/2018). ${ }^{3}$
\end{abstract}

\title{
3. OS MÉTODOS
}

\subsection{O livro aberto e a abstração}

Os exercícios fundadores propostos aos alunos, cujo objetivo principal é ensinar a ver, baseiam-se na realização de uma meticulosa análise de objetos da natureza, com suas formas e seus padrões geométricos, ora explícitos, ora disfarçados ou quase ocultos. Para Antoni Gaudí, “O grande livro, sempre aberto, e que convém esforçarmo-nos para ler, é o da Natureza; todos os demais surgiram deste e têm, para além do mais, as interpretações e equívocos dos homens" (apud PUIG, 2011, p. 25, tradução nossa).

Figura 5: análise de formas e padrões dos objetos da natureza.
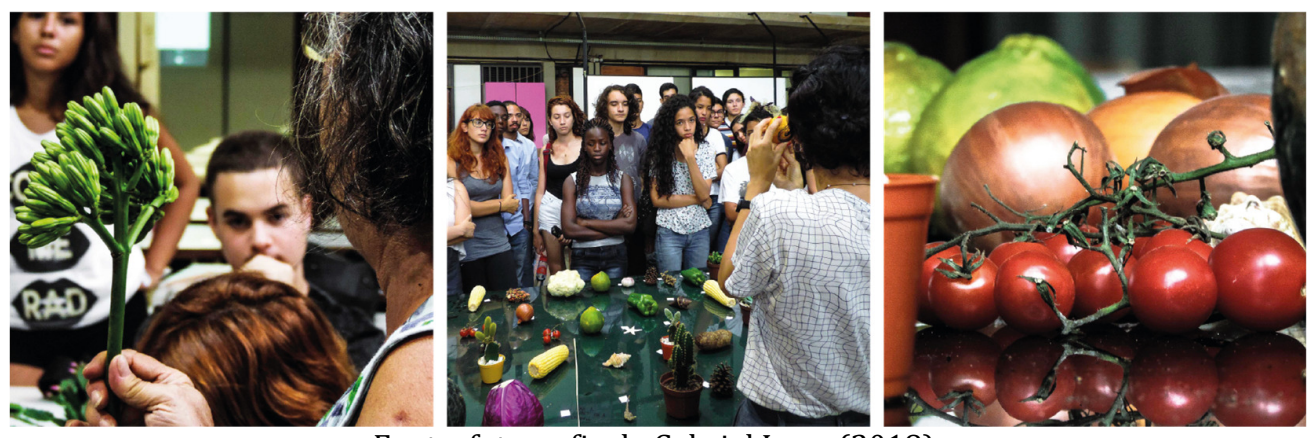

Fonte: fotografia de Gabriel Lyon (2018).

0 reconhecimento das características dos objetos da natureza, pródiga na provisão de elementos para a fantasia humana recombinar livremente, possibilita uma importante experiência tátil-visual. Além de contribuir para o enriquecimento do repertório formal, o contato vis-à-vis com os elementos orgânicos e a percepção de suas diferentes texturas, como

\footnotetext{
${ }^{3}$ Os depoimentos dos alunos estão em itálico para diferenciar das demais citações.
} 
liso, rugoso, áspero, brilhante, opaco etc., promove um refinamento da capacidade sensorial.

Para que possa ser devidamente apreciada e avaliada, essa análise é feita por meio de uma série de registros gráficos, divididos em duas etapas: a primeira, mais empírica e intuitiva, corresponde ao desenho de observação, o mais fiel possível, do objeto estudado (arte como imitação) ${ }^{4}$; a segunda, mais racional e investigativa, consiste em procurar reconhecer as formas e padrões geométricos expressos nesse objeto (arte como criação) ${ }^{5}$.

[...] o ensino do desenho visa desenvolver o hábito da observação, o espírito de análise, o gosto pela precisão, fornecendo-lhes meios de traduzirem ideias e de os predispor para as tarefas da vida prática, concorrerá também para dar a todos uma melhor compreensão do mundo das formas que nos cercam (COSTA, 1942, p. 3).

Figura 6: desenhos de observação dos objetos da natureza.
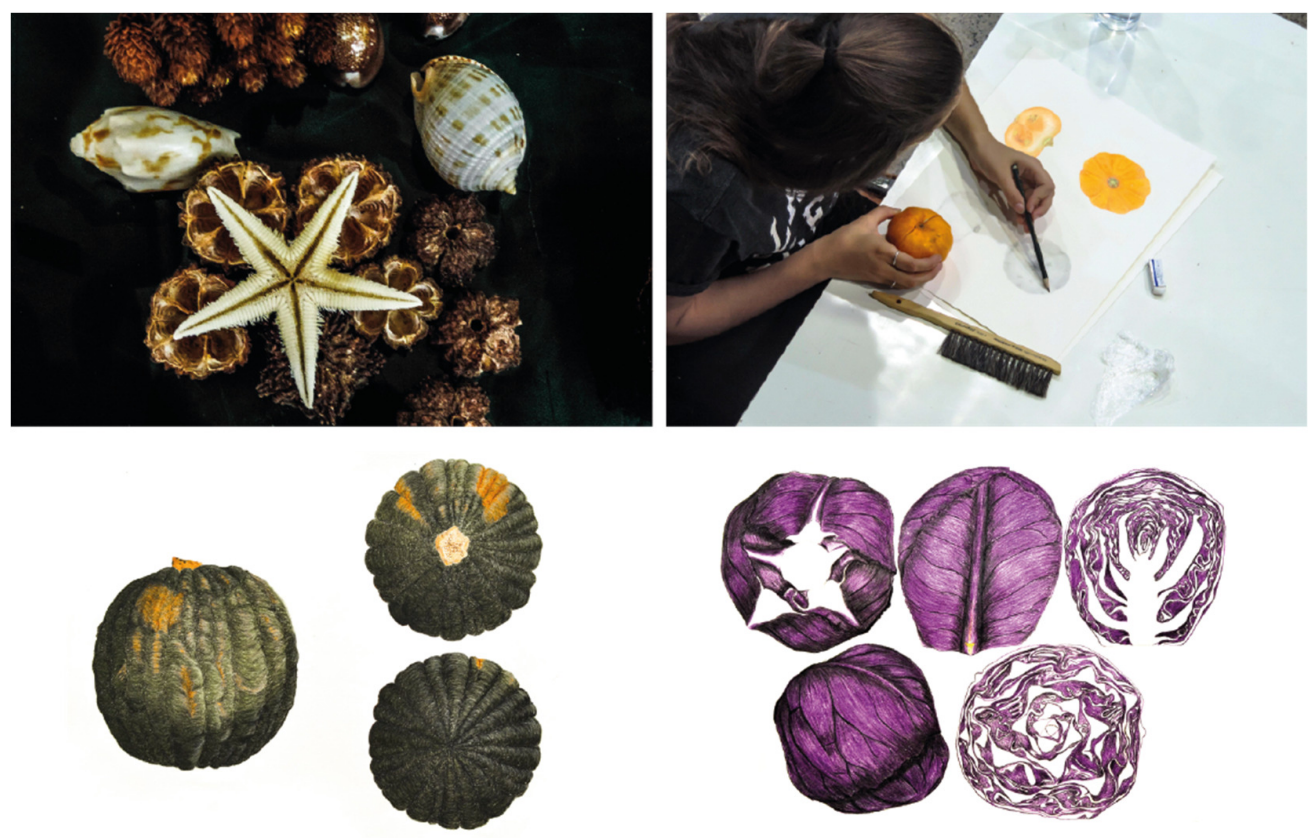

Fonte: fotografia de Gabriel Lyon (2018).

Concluídas essas etapas analíticas, os alunos passam a dispor de um farto material, composto de formas geométricas simples, isoladas, e também de padrões complexos, que resultam de como estas se juntam e se interpenetram. Até aqui, os alunos estão na condição de criaturas, que tentam interpretar os objetos da Criação.

0 principal instrumento da segunda fase do processo de análise é, sem dúvida, a geometria. Pontos, linhas retas e curvas, triângulos, quadrados, círculos, espirais etc. tornam-se códigos para o registro das formas e padrões

\footnotetext{
${ }^{4}$ Conceito que remete à visão de Platão, que concebeu a arte como totalmente subordinada à natureza.

${ }^{5}$ Conceito que remete à visão de Hegel, que viu a arte como resolução de problemas estéticos, com vistas a uma nova condição espiritual.
} 
da natureza. É o momento da geometrização do "objeto" orgânico registrado pela observação. Seguindo Cézanne, que propôs “[...] tratar a natureza conforme o cilindro, a esfera, o cone" (apud CHIPP, 1988, p. 16), busca-se identificar, nos objetos estudados, sua geometria, suas características, e ainda os ritmos decorrentes da repetição de elementos, ou seja, os padrões de ordem por meio dos quais a natureza é disciplinada.

Figura 7: processos de geometrização a partir dos desenhos de observação.

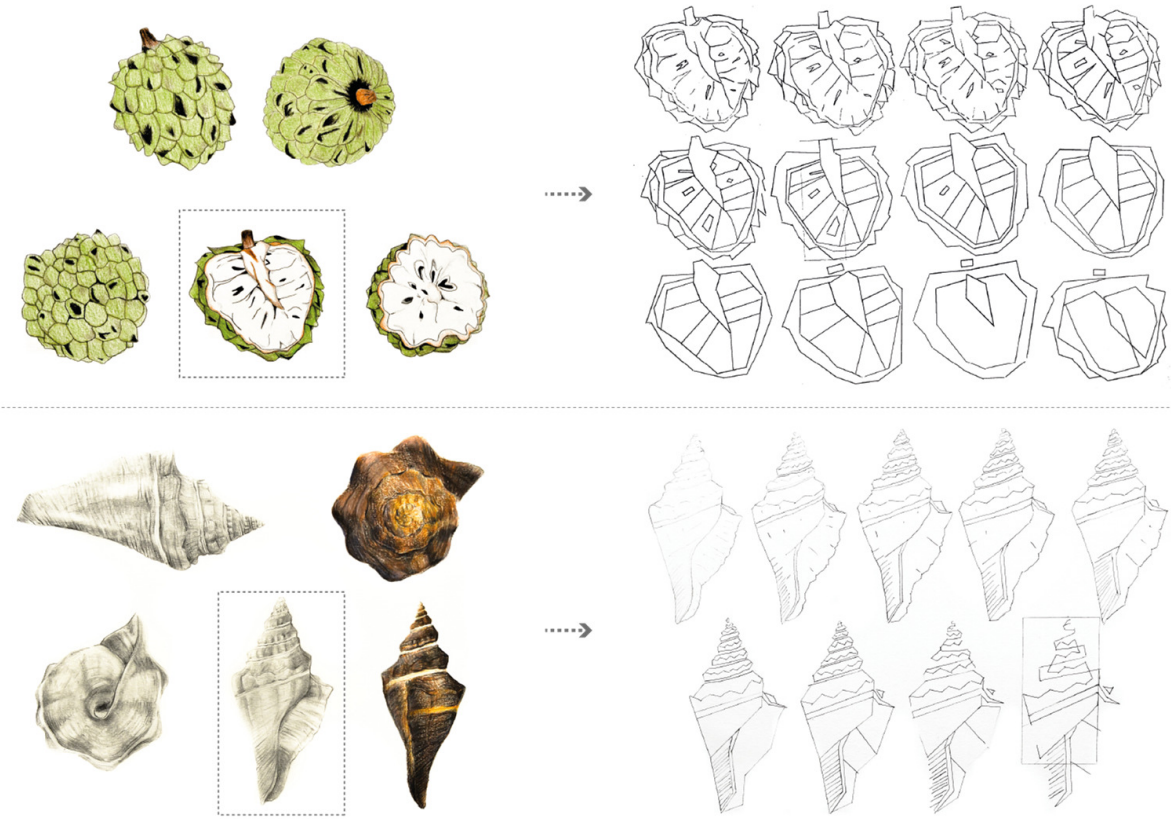

Fonte: fotografia de Gabriel Lyon (2018).

Ao invés de tratar a geometria como um fim em si mesmo, o desenho geométrico se faz presente somente nos momentos em que há necessidade de reconhecimento e representação das diferentes formas e padrões. Com isso, vão surgindo os arcos tangentes, as elipses, os círculos, os quadrados, os trapézios e todos os demais "personagens" que deverão integrar as composições plásticas. Uma vez que suas regras e conceitos não são transmitidos de forma teórica e isolada, e sim diretamente vinculados à solução de problemas concretos, a geometria, tida frequentemente como um assunto hermético, afeto a alguns poucos eleitos, torna-se agradável para os que dela se apropriam.

Paralelamente à geometrização, e se confundindo com ela, desenvolve-se o processo de abstração, primeiro elemento do tripé metodológico pensado para a disciplina. Segundo o arquiteto Carlos Martí Arís (2000), abstração corresponde a um procedimento cognitivo que tende a separar os aspectos acidentais ou contingentes dos essenciais ou necessários, permitindo extrair um conceito universal a partir de diversas situações ou objetos particulares. Sendo assim, a abstração decorre de duas intenções: isolar a coisa previamente escolhida daquelas com as quais mantém relação, e assumir como objeto específico de consideração aquilo que foi isolado. 
Assim, qualquer operação analítica que comporte a substituição das partes de um todo por entes geométricos ou a decomposição de um todo em seus elementos básicos implica um grau de abstração.

Após o que na época pareceram meses, meu desenho de observação foi aceito e eu pude partir para a próxima, e arrisco dizer, a mais importante etapa da disciplina: a geometrização. Nesse momento, eu já me encontrava tão familiarizada com minha beterraba que o modo como eu a via era outro. Suas formas saltavam naturalmente aos meus olhos, e o que antes era o contorno de um simples vegetal transformava-se em composições abstratas bidimensionais $e$ tridimensionais. A matéria que havia antes me deixado noites inteiras acordada agora me trazia um prazer autêntico [...] Fico contente de imaginar minha reação, se eu pudesse compartilhar agora, com aquela caloura receosa e seu vegetal, a importância daquela beterraba não só para minha formação como arquiteta, mas também para a aquisição de um modo diferente de enxergar o mundo. (Depoimento da aluna Teresa Bernadete Medina Ferreira. Títulos das obras: Primavera e Convergência, 2º /2017)

Com origem no desenvolvimento de novas formas de apropriação do real, a abstração contribui para ampliar a capacidade tátil-visual e intelectual e também para ampliar as possibilidades de criação. 0 esforço cognitivo, que implica afastamento ou subversão do real, tão importante para as atividades artísticas em geral, é condição sine qua non para as práticas da arquitetura e do design.

\subsection{O jogo do quebra-cabeça}

$\mathrm{Na}$ fase seguinte, os alunos começam a dar vazão à sua vocação criativa ou, como queria Gaudí ao se referir à arquitetura, são convidados a continuar a Criação: "[...]não invente soluções, mas observe como a natureza se organiza [...] Se a natureza é um feito do Criador e as formas arquiteturais derivam da natureza, isto significa que o Criador está sendo continuado" (apud PUIG, 2011, p. 25, 27). Esse pensamento do papel do ser humano como continuador da obra divina foi explorado, de forma bem-humorada, por Domenico de Masi: “[...] se Deus pôde se permitir um sétimo dia de repouso, foi porque o homem assumiu a honra de prosseguir a criação incompleta [...] seis bilhões de cérebros adormecem e começam a sonhar formas, acordam e começam a pensar em como traduzir na prática esses sonhos" (2003, p. 338).

Finalmente, é chegada a etapa de síntese do processo de aprendizado (arte como construção) ${ }^{6}$, em que o aluno (o artista) torna-se o protagonista da criação, a ser expressa por meio da composição plástica. Compor significa agrupar, organizar, coordenar; e plástica remete a dar forma, transformar, modelar ${ }^{7}$, podendo-se a partir daí definir a composição plástica como uma

\footnotetext{
${ }^{6}$ Conceito que remete à visão de Kant. Para o filósofo, a arte, embora não prescindisse da natureza, subordinava-a a si, fazendo com que o artista se tornasse um importante protagonista dessa transformação. 7 Dicionário Aurélio.
} 
organização e distribuição harmoniosa dos elementos que compõem a obra de arte.

[...] ao formar, ao dar forma à imagem, o artista é obrigado a deformar. Por necessidade substituirá as formas existentes na natureza por outras. Também criará novos contextos formais, cuja extensão e equilíbrio irão servir de padrão de referência à própria interpretação das formas articuladas pelo artista [...]. Mesmo querendo inspirar-se em formas da natureza, o artista as abandona para criar formas de linguagem. (OSTROWER, 2004, p. 314).

Trata-se, portanto, de produzir composições ou rearranjos a partir das formas e padrões observados e registrados nas fases analíticas. E, para que aquelas resultem plasticamente harmoniosas, faz-se necessário algum domínio dos requisitos estéticos que compõem o universo das artes plásticas. Nesse momento, é importante ainda conhecer o que a humanidade produziu no campo da arte abstrata e de que formas ou por que motivos o fez.

Além de adquirir maior domínio dos entes geométricos, como ponto, linha, superfície, volume, é preciso que os alunos compreendam o significado das estratégias compositivas - proporção, simetria-assimetria, claro-escuro, figura-fundo, equilíbrio, ritmo, unidade, contraste, peso etc. - e sejam capazes de identificá-las nas obras de arte e usá-las em seus próprios estudos.

Mas a tarefa de criar a composição é um pouco mais complexa. Das lições tiradas das formas orgânicas, pode-se perceber, como afirmou Paul Weiss, que "[...] a natureza não é caótica e atomizada. Seus padrões são primários e inerentes e a ordem fundamental de beleza é aparente". A natureza ensina que o belo sugere mais que uma simples ordenação: o belo especifica, segundo o autor, "[...] uma ordem compatível com a singularidade, somente apreendida pela mente humana porque ela própria é parte desta ordem" (WEISS, 1960, p. 20, tradução nossa). A natureza precisa da ordem para garantir a reprodução das espécies e, ao mesmo tempo, da variedade para que possa se fazer instigante e bela.

Se couber aqui uma analogia com a música, pode-se dizer que a ordem está explicitada no tema ou na melodia da composição e que a singularidade corresponde à harmonia ou à improvisação. Nesse sentido, para produzir uma obra de arte, para gerar beleza, não basta reproduzir determinada ordem, ou fazer a mera releitura dos padrões geométricos orgânicos, é necessário e desejável que se estabeleça uma coexistência harmoniosa entre as diretrizes ordenadoras e os elementos singulares, propostos pelos criadores. Se por um lado a falta de ordem conduz ao caos, o excesso dela enseja monotonia e, por consequência, desinteresse por parte dos espectadores de arte. 
Figura 8: recortes e rearranjos de formas feitos a partir dos processos de geometrização.

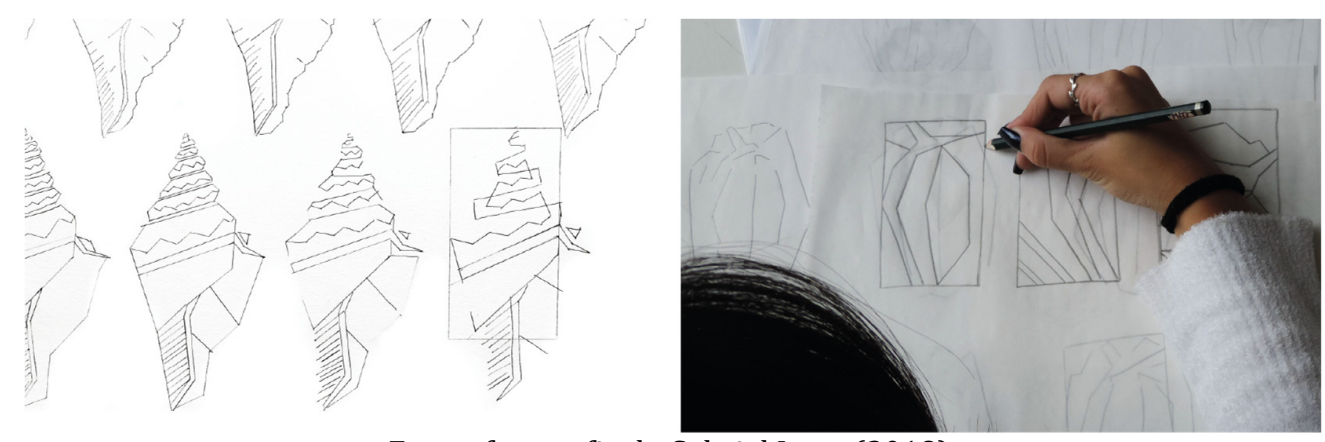

Fonte: fotografia de Gabriel Lyon (2018).

Além disso, é preciso conhecer os fenômenos e os limites da percepção humana. E, nesse sentido, torna-se necessário dar a conhecer as leis da Gestalt, desenvolvidas com base na constatação da existência de distorções visuais, causadas pelo fato de a visão não ocorrer a partir da projeção em uma tela estendida, e sim de projeções em cada um dos dois globos oculares.

Os estudos da Gestalt procuram compreender a "agradabilidade visual" de modo a transformá-la em uma ferramenta útil, que permita trabalhar com o senso comum e com a possibilidade de universalização de julgamento quando da apreensão da obra de arte:

Há algo que transcende a um exclusivo gosto pessoal ou a um
gosto na dependência de um momento histórico. Só em função de
alguma constante pode-se explicar que o homem realize e perceba
a beleza, quer seja através de uma escultura primitiva, uma
estátua grega ou de uma composição de nossos dias.
(FRACCAROLI, 1982, p. 27).

Definido o arranjo formal, é hora de chamar a atenção para o papel das cores na composição plástica, que ganha um considerável suporte a partir sobretudo das hipóteses formuladas no Esboço de uma teoria das cores (1810), de Johann Wolfgang von Goethe, retomadas pelo químico francês Michel Eugène Chevreul em 0 tratado das cores: a lei do contraste simultâneo (1839). No início do século XX, vários artistas, entre os quais Johannes Itten, Paul Klee e Wassily Kandinsky, fornecem contribuições significativas para a compressão da percepção humana sobre o fenômeno cromático.

No entanto, independentemente desses aportes teóricos, as decisões sobre a escolha e o uso das cores são tomadas, na disciplina, a partir de exercícios experimentais, com base na tentativa e erro, o que contribui para explicitar as transformações por que passam as composições em função dessa escolha, no que diz respeito a proporção, profundidade, tridimensionalidade etc. Por vezes o lançamento cromático valoriza as linhas, por outras, os planos. E uma mesma composição, dependendo das cores que lhe são agregadas, pode transmitir diferentes sensações. Os estudos, feitos com lápis de cor pelos alunos, servem para demonstrar como as cores 
interferem, de forma decisiva, na composição plástica e, consequentemente, no conteúdo a ser comunicado.

Figura 9: estudos de cor para os arranjos escolhidos.
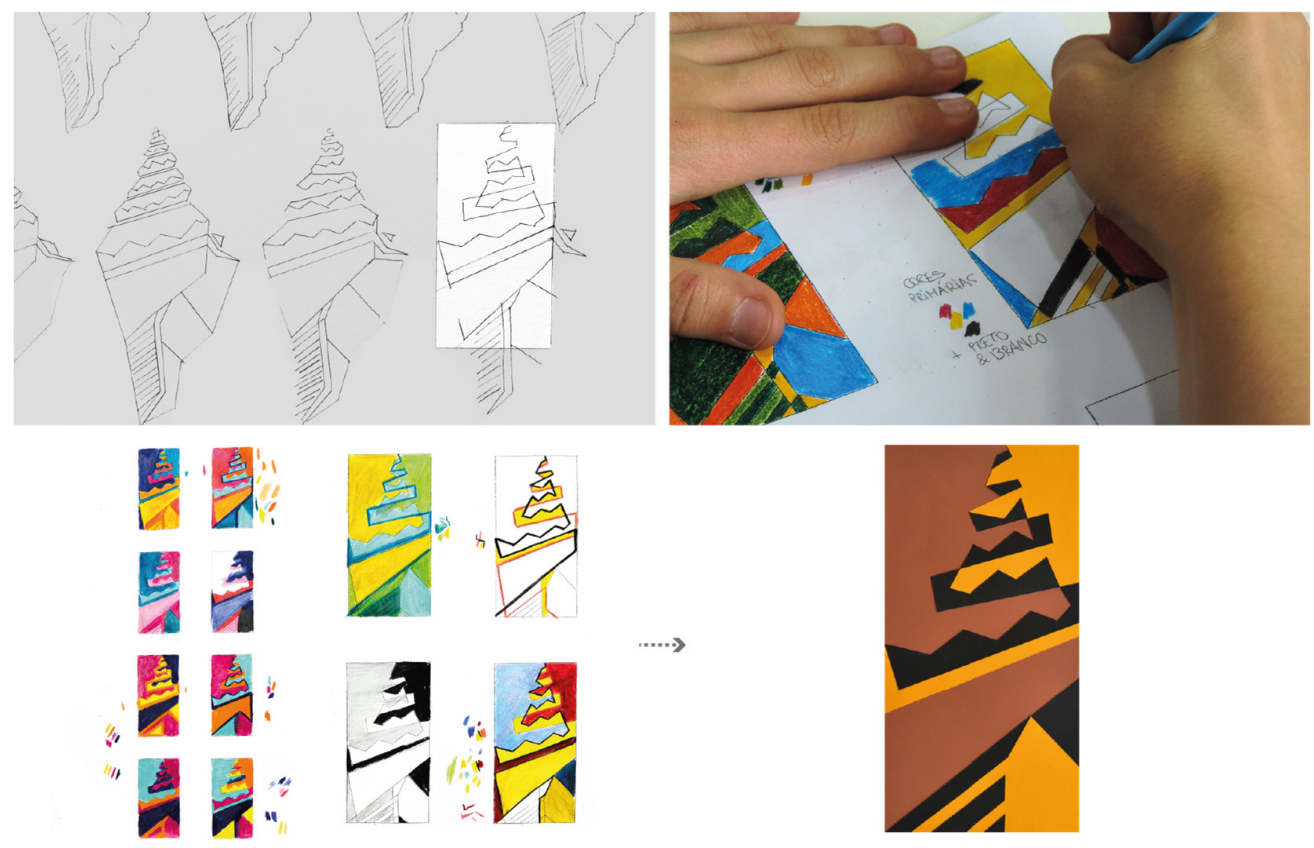

Fonte: fotografia de Gabriel Lyon (2018).

Os muitos elementos e a necessidade de trabalhar com uma ordem aliada à variedade transformam essa etapa em um verdadeiro jogo, melhor dizendo, em um complexo quebra-cabeça. É aí que entra em cena o caráter lúdico, o segundo elemento que compõe o tripé metodológico adotado como suporte das atividades pedagógicas. 0 fato de as peças e as regras estarem colocadas não garante o sucesso da produção artística. Como em qualquer jogo, não basta conhecer peças e regras, é preciso certa perspicácia, que, nesse caso, prefere-se chamar de criatividade.

O lúdico, como fator de extrapolação ou subversão da realidade cotidiana, implica uma forma subliminar de desenvolvimento intelectual, que está na gênese do pensamento, da descoberta de si mesmo, da possibilidade de experimentar e criar.

o processo de criação é a parte mais desafiadora. A cada orientação, a cada incerteza sobre se a escultura iria ficar em pé, a cada pedido pra refazer, eu via o meu trabalho tomando forma e, no fim, senti que havia feito algo que nunca teria sonhado em realizar. Os meus limites foram puxados até que a minha essência estivesse presente na obra. Nunca fui uma pessoa muito segura sobre o meu talento e as coisas que faço. A disciplina, além de abrir meus olhos para a infinidade de cores, formas e composições do mundo da geometria, ensinou-me a acreditar mais em mim mesmo e no meu potencial. (Depoimento do aluno Vitor Silvério Prado. Título das obras: Nascente e Tormento, 2o2018). 
Como observa Domenico De Masi, "A principal característica da atividade criativa é que ela praticamente não se destaca do jogo e do aprendizado, ficando difícil separar essas três dimensões que antes, em nossa vida, tinham sido separadas de maneira clara e artificial” (2000, p. 10).

Johan Huizinga afirma que "[...] o jogo se baseia na manipulação de certas imagens, em uma certa 'imaginação' da realidade, (ou seja na transformação desta em imagens)". 0 jogo contribui para a percepção: do tempo, "[...] enquanto está decorrendo, tudo é movimento, mudança, alternância, sucessão, alteração, separação"; do espaço "[...] todo jogo se processa no interior de um campo delimitado, de maneira material, ou imaginária, deliberada ou espontânea"; e da ordem "[...] o jogo cria ordem e é ordem. Introduz na confusão da vida e na imperfeição do mundo uma perfeição temporária e limitada" (HUIZINGA, 2000, p. 7, 8, 11), proporcionando, ainda que provisoriamente, uma sensação de tranquilidade e segurança. E conclui:

É talvez devido a esta afinidade entre a ordem e o jogo que este parece estar, em tão larga medida, ligado ao domínio da estética. Há nele uma tendência para ser belo. Em suas formas mais complexas, o jogo está saturado de ritmo e de harmonia, que são os mais nobres dons de percepção estética de que o homem dispõe. São muitos, e bem íntimos, os laços que unem o jogo e a beleza. (HUIZINGA, 2000, p. 14).

\subsection{A mão na massa}

Cada aluno, na condição plena de Criador, torna-se responsável pela síntese, que traz em si as técnicas necessárias à materialização do ato criador. E basta uma sensibilização sobre características/propriedades dos materiais para fazer com que as criações se transformem em objetos esperando para serem reconhecidos como obras de arte.

Figura 10: registro da etapa de materialização das ideias com a produção de protótipos bi e tridimensionais.
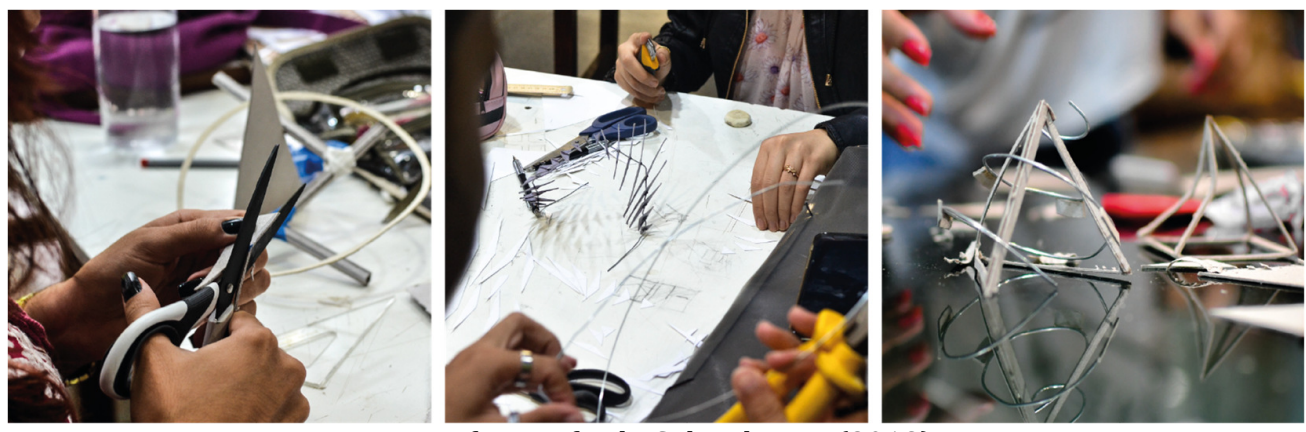

Fonte: fotografia de Gabriel Lyon (2018).

Definidas as formas e cores das composições bi e tridimensionais, é chegado o momento de cada aluno encarar o desafio da materialização das ideias, anteriormente expressas por meio de layouts e protótipos. No caso dos 
trabalhos bidimensionais, surgem algumas opções que vão da colagem (em papel ou folheados de madeira) à serigrafia, passando pela pintura. Alguns poucos chegam, até mesmo, a serem executados com base na técnica de string art (arte feita com linhas trançadas sobre tábuas de madeira com pregos).

Em relação aos trabalhos tridimensionais, as dificuldades de materialização são maiores, pois é preciso estar atento para as propriedades intrínsecas a cada material, sobretudo em relação à resistência, já que as "esculturas" devem ficar em pé, sem o auxílio de uma base de apoio, aposta e estranha à composição. Partindo de protótipos em escala real, feitos após uma série de modelos reduzidos em papel, são discutidos com os alunos os materiais que melhor poderiam expressar as ideias propostas.

Dependendo das dificuldades de execução, os alunos apelam para a ajuda de profissionais, como marceneiros, serralheiros etc., que possam executar essas tarefas. Muitas vezes, membros da própria família, dominando ou não os ofícios, se dispõem a ajudá-los. Surgem então trabalhos em madeira, aço, acrílico, vidro, pedras, etc., e mesmo um ou outro feito com sucata. Neste último caso, já houve até a colaboração de artistas plásticos locais, que construíram, juntamente com os alunos, em suas próprias oficinas, os objetos criados.

A participação da família contribui para aumentar a autoestima e a autoconfiança dos alunos. A colaboração dos artistas e principalmente dos profissionais é também bastante positiva, pois além de permitir um intercâmbio entre o mundo acadêmico e a sociedade, possibilita um diálogo entre os alunos e aqueles que, de fato, põem a mão na massa, resultando na aquisição de um vocabulário próprio do universo do fazer e conscientizando os estudantes sobre as dificuldades concretas para a execução de suas ideias.

Essas situações constituem minúsculos exemplos de como, por meio da prática pedagógica, é possível reduzir a distância entre o pensar e o fazer, contribuindo para que a universidade, além de produzir conhecimento, possa transformá-los em produtos reais.

Figura 11: etapas do método.
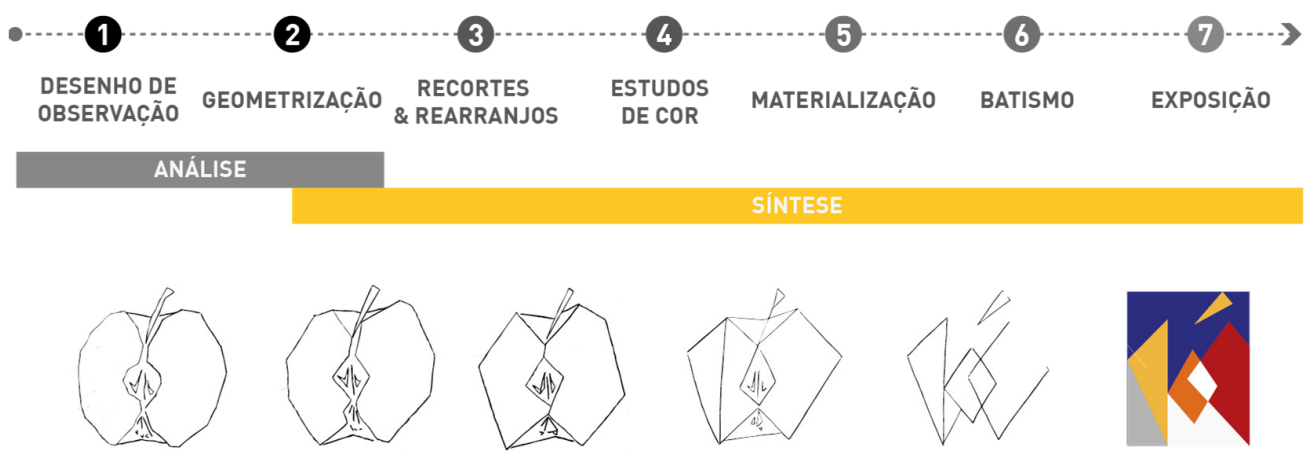

Fonte: diagrama elaborado pelos autores. Fotografia de Gabriel Lyon (2018). 


\subsection{Os sonhos e fantasias}

Com um repertório compositivo mais consolidado, chega a hora de dar asas à imaginação e se aventurar pelo campo da criação de forma mais liberta. Surgem, então, as fantasias... manifestações do espírito que, emergindo dos cérebros criativos, impregnam, por meio da construção de objetos plásticos, a realidade do nosso espaço vital.

Poesias, danças, cidades, atividades circenses e o próprio carnaval têm sido pretextos para o despertar de emoções e inspirar essa nova etapa dos trabalhos. Sentimentos como tristeza, alegria, dor, prazer concorrem para estimular a sensibilidade e a subjetividade de cada um, fazendo desencadear um processo diferenciado de criação.

Apesar de a metodologia utilizada ser, de certo modo, semelhante à anteriormente descrita, o desafio do processo de abstração nesta etapa é preservar a identidade do tema proposto para o exercício, de modo que o espectador consiga reconhecê-lo. Assim, enquanto os produtos derivados de elementos da natureza indicam um abstracionismo geométrico, os resultantes das manifestações culturais expressam um abstracionismo lírico, mais adequado ao resgate cognitivo e simbólico de tais manifestações e de seus personagens emblemáticos.

Figura 12: trabalhos finais inspirados nos temas "dança", "obra do artista" e "cidades".
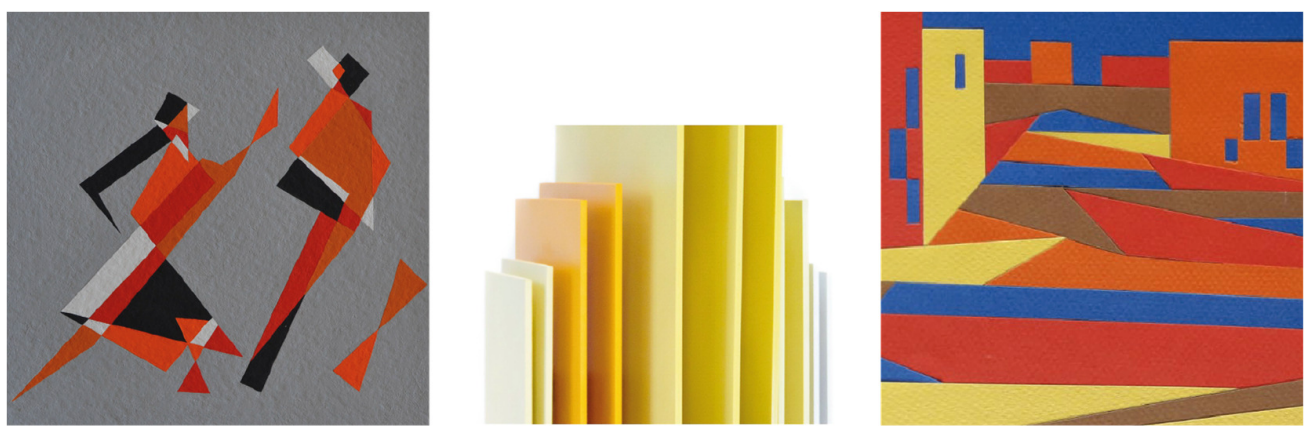

Fonte: fotografia de Gabriel Lyon (2018).

As afinidades individuais com as expressões culturais e os estados mais ocultos do espírito criativo sugerem, nesse caso, uma pesquisa diferenciada, que objetiva a construção de símbolos, a serem transpostos posteriormente para o campo da matéria.

Um dos temas usados para esse exercício foram as cidades invisíveis, descritas pelo escritor Italo Calvino (1991). Apesar de, no geral, os resultados terem sido considerados satisfatórios, observou-se a dificuldade de alguns alunos para interpretar os textos herméticos e carregados de simbolismo do autor. Por outro lado, as experiências baseadas em cidades reais geraram trabalhos interessantes que, apesar do exaustivo processo de abstração, foram capazes de manter elementos suficientes para identificação destas.

Com o objetivo de explorar o movimento e imprimir um caráter mais dinâmico às composições, utilizaram-se como temas diversos exemplos de dança e atividades circenses e carnavalescas. 0 objetivo subjacente à escolha 
dessas temáticas foi a observação e o registro da movimentação dos corpos humanos no espaço. Considera-se que as experiências foram bem sucedidas, tendo produzido obras de franco apelo visual. Embora os trabalhos tridimensionais tenham suscitado maiores dificuldades de execução, os resultados foram surpreendentes.

Mais recentemente, a construção de fantasias teve como origem obras de artistas consagrados, que usam a abstração como ferramenta para o trabalho criativo. Após a realização de análises dessas obras, usando os conceitos próprios da composição plástica, os desafios foram produzir esculturas a partir da releitura de obras bidimensionais e criar pinturas, colagens etc. a partir de obras tridimensionais. Com isso, além da apreensão dos conceitos que regem o fazer artístico e do destaque dado ao movimento e ao ritmo, buscou-se estimular a capacidade de transformação de espaços tridimensionais em bidimensionais, por meio do desenho, ou de espaços bidimensionais em tridimensional, por meio da realização de protótipos.

A despeito dos objetivos mais específicos, referentes às particularidades de cada tema, a ideia com esses exercícios foi dar vazão aos sonhos e fantasias dos estudantes, introduzindo-se então o terceiro elemento do tripé metodológico: a utopia.

Herbert Marcuse admite que, ao insistirem no valor dos sonhos, os artistas defendem que as imagens da liberdade e satisfação ainda não alcançadas estariam presentes como ideias reguladoras da razão, do pensamento e das práticas pela reconstrução dos valores sociais. Ao passo que a realização progressiva do sonho e sua preservação são tarefas da luta por uma sociedade melhor, sustentar o sonho contra uma sociedade que não sonha é a grande função subversiva da arte, que ele chama de "promessa de felicidade". Para o autor, "[...] o artista dissocia-se metodicamente da sociedade alienada e cria o irreal, universo 'ilusório' no qual a arte por si só tem e comunica sua verdade" (MARCUSE, 1986, p. 97).

É sonhando com um mundo mais justo e fraterno que os artistas e os arquitetos podem construir talvez o seu mais importante legado. Mas desenhar essas utopias não é uma tarefa fácil: "[...] exprimir um sonho, uma fantasia, é uma operação de alta matemática, como lançar uma nave no espaço. A expressão exige um máximo de rigor" (FELLINI, 1995, p. 97).

Ter coragem para pensar alto e investir na utopia constituem exercícios próprios de um ser irrequieto e investigativo, e acreditar no sonho é o incentivo maior para o desabrochar de mentes criadoras.

\section{AS PALAVRAS FINAIS}

Mais poderia ser dito sobre essas experiências pedagógicas cujo pressuposto é o espírito lúdico, que usa a abstração como ferramenta para a construção de utopias. 
Cada resultado parcial constitui um experimento e um produto, configurando uma estratégia que, valorizando ambos, tem no primeiro a criatividade e no segundo a necessidade de comunicação das criações resultantes. À ebulição cerebral própria do ato criativo contrapõe-se o fazer manual que, resgatando o equilíbrio psíquico, contribui para desenvolver a coordenação motora fina e estimular a aprendizagem.

Considerando que artistas e arquitetos devem ter um compromisso com os horizontes futuros, ao acolher a ordem e a geometria como meios pretende-se, como fim, conduzir o processo de aprendizado a um avanço no campo da liberdade plástica, da criatividade, enfim, da construção de fantasias.

Propor diferentes respostas para um mesmo problema, ou antecipar cenários e inventar soluções possíveis ou impossíveis, faz parte do processo de especulação a ser estimulado no universo acadêmico. É o lançamento de ideias, por meio de muitas tentativas e erros, que faz com que os alunos, acumulando experiências, se qualifiquem como construtores de uma sociedade melhor.

\section{REFERÊNCIAS BIBLIOGRÁFICAS}

ARÍS, Carlos Martí. Abstracción en arquitectura: una definición. Barcelona: Universitat Politecnica da Catalunya/DPA, 2000. Disponível em: https://issuu.com/maearq_med/docs/dpa16_abstraccion. Acesso em: 12 fev. 2019.

BAUMAN, Zygmunt. Modernidade líquida. Rio de Janeiro: Zahar, 2001.

CALVINO, Italo. As cidades invisíveis. São Paulo: Companhia das Letras, 1991.

CHIPP, Herschel Browning. Teorias da arte moderna. São Paulo: Martins Fontes, 1988.

COSTA, Lucio. Ministério da Educação e Saúde, Instituto Nacional de Estudos Pedagógicos (INEP). Desenho [programa de desenho para o ensino secundário]. Rio de Janeiro: Arquivo Gustavo Capanema CPDOC/FGV, 1942.

DE MASI, Domenico. 0 ócio criativo. Rio de Janeiro: Sextante, 2000.

. Criatividade e grupos criativos. Rio de Janeiro: Sextante, 2003.

FELLINI, Federico. Eu sou um grande mentiroso: entrevista a Damien Pettigrew. Rio de Janeiro: Nova Fronteira, 1995.

FRACCAROLI, Caetano [1952]. A percepção da forma e sua relação com o fenômeno artístico: o problema visto através da Gestalt (psicologia da forma). São Paulo: FAUUSP, 1982.

GOROVITZ, Matheus. Da educação do juízo de gosto. Revista Brasileira de Estudos Pedagógicos, Brasília, v. 79, n. 193, 1998. Disponível em: 
http://rbep.inep.gov.br/index.php/rbep/article/view/1020/994. Acesso em: 27 fev. 2019.

HUIZINGA, Johan. Homo ludens. São Paulo: Perspectiva, 2000.

MARCUSE, Herbert. A dimensão estética. Tradução de: Maria Elisabete Costa. Lisboa: Edições 70, 1986.

OSTROWER, Fayga. Universos da arte. 24. ed. Rio de Janeiro: Elsevier, 2004.

PALLASMAA, Juhani. As mãos inteligentes: a sabedoria existencial e corporalizada na arquitetura. Trad. Alexandre Salvaterra. Porto Alegre: Bookman, 2013.

PUIG, Armand. La Sagrada Familia según Gaudí. Barcelona: El Aleph Editores, 2011.

SARAMAGO, José. A caverna. São Paulo: Cia das Letras, 2000.

WEISS, Paul. Organic forms: scientific and aesthetic aspects. In: KEPES, Gyorgy (ed.). The visual arts today. Middletown: Wesleyan University, 1960, p. 177-190.

\section{AGRADECIMENTOS}

Agradecemos à Irene Ernest Dias pela revisão e formatação textual e ao Gabriel Lyon pelas fotos e tratamento das imagens. 